\title{
Monitoring quality of service at Australian airports: A critical analysis
}

\author{
Dr Jakob Trischler \\ Karlstad University \\ CTF Service Research Center \\ 65188 Karlstad \\ Universitetsgatan 2 \\ Sweden \\ jakob.trischler@kau.se
}

\author{
A/Prof Gui Lohmann \\ Program Director, Postgraduate Aviation Management Degrees \\ Griffith Aviation, Griffith University \\ g.lohmann@griffith.edu.au
}

\begin{abstract}
The quality of service monitoring forms a key element of the current light-handed regulation at Australian airports. The ACCC (Australian Competition and Consumer Commission) evaluates and publicly reports the quality of service levels of the four largest airports on a yearly basis to pressure airports to maintain an acceptable service performance. This article aims to provide an in-depth analysis of the methodology used by the ACCC. This analysis includes a critical review of the methodology based on secondary information in combination with primary research (i.e., data from 21 semi-structured interviews) that considers the current perception of the methodology among key stakeholder groups. The research finds that the methodology used by the ACCC is underpinned by some limitations, putting in question its effectiveness, reliability and validity. Particularly, its weak design does not allow for a comprehensive interpretation of the reported results or a reliable comparison across monitored airports, thus reduces transparency. Stakeholders pointed out that it is not possible to evaluate whether an airport undertakes infrastructure investments that ensure both the efficiency of ongoing airport operations and appropriate levels of service quality. These limitations add to the perception that the ACCC in its current function is not a 'credible threat' to airports with market power. Recommendations and future research directions are provided to address the identified limitations.
\end{abstract}

Keywords: quality of service monitoring, Australian Competition and Consumer 
Commission, light-handed regulation, airport service quality

Highlights

- In-depth analysis of the service quality methodology used by the ACCC

- The methodology used by the ACCC is underpinned by some limitations

- Its weak design does not allow for a comprehensive interpretation of the results

- Perception that the ACCC is not a 'credible threat' to airports with market power

\section{Introduction}

One key element of the light-handed regulation (LHR), as currently in place at Australia's top four airports (i.e., Brisbane, Melbourne, Perth, Sydney), is the monitoring of quality of service. The LHR does not involve formal price regulation or place any immediate constraints on aeronautical charges but instead monitors airport prices and quality of service levels (Littlechild, 2012). Also, it carries the threat of re-imposing stricter regulation in cases where an abuse of market power is evident (Gillen, 2011). A main objective of the LHR is to overcome the drawback of conventional regulation frameworks imposing few incentives for the regulated enterprise to pursue productive efficiency (Vogelsang, 2002). Specifically, in Australia, the LHR aims to a) foster commercial negotiations between airport operators and their customers; b) decrease the costs of administration; and c) encourage airports to undertake infrastructure investments that ensure both efficiency of ongoing airport operations and appropriate levels of service quality (Arblaster, 2014; Lohmann and Trischler, 2017). The present article focuses on airport quality of service, including its monitoring approach as used by the ACCC.

In its latest report, the Productivity Commission (PC) did not reach any conclusions regarding the quality of service levels at Australia's monitored airports, apart from the observation that the airports have performed 'relative to each other' (Productivity Commission, 2011). This lack of analysis is somewhat troublesome when considering that quality of service levels among the four airports has brought mixed results since the start of the monitoring regime in 2001 (ACCC, 2016). In addition, the monitoring of service quality forms a key aspect of the LHR because this regime encourages airports to increase profits. One possible way to do this is by allowing service levels to fall through underinvestment (Francis et al., 2002; Adler et al., 
2015). The argument that revenues from concession services, such as retailing, car parking and catering, might deter an airport from decreasing quality of services or delay infrastructure investments is not sufficiently grounded (Fu et al., 2011).

Based on the limited attention given to quality of service as a key element of the LHR framework, the purpose of the present research is to provide an in-depth analysis of the methodology used by the ACCC to monitor the quality of service at the four Australian airports. The analysis includes a critical review of the methodology with secondary information in combination with primary research that considers the current perception of the monitoring approach among key stakeholder groups. These are representatives from Australia's major airports and airlines, government regulatory bodies, national aviation associations and leading Australian academics within the underlying field.

The research is timely and relevant considering the publication of the latest guidelines developed for monitoring the quality of service (ACCC, 2014), as well as the mixed responses to the methodology from the airline industry (e.g., Board of Airline Representatives of Australia, 2012; Qantas Airways, 2012) and airports (e.g., Finch et al., 2010; Brisbane Airport Corporation, 2012). Notably, quality of service is a multidimensional construct (Bezerra and Gomes, 2016) and is perceived differently depending on the respective customers' needs and preferences (Pantouvakis and Renzi, 2016). In its in-depth analysis of the methodology used by the ACCC, the present article takes these aspects into account. Thereby, the analysis focuses on the monitoring of airport services provided to passengers and airlines respectively. However, it excludes car parking and landside services which, while relevant service components, were only recently added (i.e., car parking in 2012; landside services in 2013) and are reported separately within the ACCC monitoring reports. Also, while the focus of this article is not on price monitoring because it follows a different methodology and is regulated by the PC, pricing is still discussed to highlight issues related to the overall perception of stakeholders concerning the current monitoring approach.

The remainder of the paper is structured as follows. The next section defines the concept of airport service quality and discusses its relevance for airports in general and for regulatory purposes in particular. The study methodology is then described, followed by an in-depth review of the approach used by the ACCC to monitor and report quality of service at airports. This review is followed by the findings from semi-structured interviews conducted with key 
stakeholders. The article concludes with discussing the theoretical and managerial implications of the findings, as well as outlining limitations and directions for future research.

\section{Literature Background}

\section{General overview of service quality at (regulated) airports}

In broad terms, airport service quality refers to the difference between a customer's expectations and the perception of the actual service received (George et al., 2013). Customers, in the context of the ACCC report, include passengers and airlines offering cargo and passenger transport services (Polk and Bilotkach, 2013). Airport service quality, particularly as perceived by passengers when travelling through an airport, has gained increasing interest among scholars and practitioners owing to its close link to a) customer satisfaction (Tsai et al., 2011; Bogicevic et al., 2013), b) airport efficiency (De Nicola et al., 2013; Merkert and Assaf, 2015), and c) non-aeronautical revenue (ACI, 2017a). In fact, airport service quality surveys are now widely used by both airport operators and regulatory authorities (Adler et al., 2015; ACI, 2016; Bezerra and Gomes, 2016).

Despite the increasing interest in airport service quality, there is no consensus regarding its actual measurement because of two main reasons. Firstly, the complicated nature of airport services implies that multiple dimensions can influence a customer's perception of service quality (Fodness and Murray, 2007). Secondly, an airport typically accommodates various customer groups with different preferences and needs (Pantouvakis and Renzi, 2016). Most studies have focused on passenger services and aggregated airport service quality into broad service dimensions. However, these dimensions differ between studies. For example, while Yeh and Kuo (2003) distinguish between six dimensions (i.e., comfort, processing time, convenience, courtesy of staff, information visibility and security), Fodness and Murray (2007) categorise service quality into three broad categories (i.e., function, interaction and diversion). More recently, Pantouvakis and Renzi (2016) use three dimensions, i.e., servicescape and image, signage, and services, but found significant differences in the perception among passengers of different nationalities. Finally, in a first attempt to develop and validate a multidimensional measurement model for airport service quality, Bezerra and Gomes (2016) distinguish between a) the performance of core airport processes (check-in and security screening), b) aspects related to the passenger-airport interaction on the passenger's movement 
through the terminal, leisure/convenience alternatives, and c) the airport servicescape.

Many airports use service quality measures for operational performance and benchmarking purposes. For example, 250 airports worldwide use the ASQ (Airport Service Quality) survey from Airports Council International (ACI) to analyse their airport's performance as well as to benchmark their results against airports within the local market and across the globe (ACI, 2017b). The ASQ Survey covers 34 key service areas categorised into eight major categories including access, check-in, security, airport facilities and food and beverage providers among others. In its reports, ACI (2017a) suggests that the close monitoring of service quality is pivotal for airports because sustaining high service standards can foster non-aeronautical revenues (e.g., revenue from rents or concession services such as retailing, restaurants, banking etc.). Also, diversification of revenue sources in an airport's financial portfolio can also serve as an important cushion during economic downturns. However, although the ACI measurement instrument is widely applied in practice, notably limited consideration has been placed on the actual reliability and validity of the instrument used (see Bezerra and Gomes, 2016 for a critique).

The monitoring of service quality also forms a key element of regulatory frameworks, especially those adopting incentive regulation approaches (Francis et al., 2002). It is significant because, in many instances, airports possess considerable market power because of the impracticality in most cases of substituting air and other transport modes (Forsyth, 2008). An unregulated airport might use its advantageous market position to invest less in the quality of services or delay infrastructure investment (Starkie, 2002). Likewise, airports operating under an incentive regulatory regime, such as the LHR, can increase profits by allowing quality to fall through underinvestment (see Adler et al. (2015) for a comprehensive assessment of the different airport regulation approaches). Consequently, to ensure that acceptable levels of service and charges are delivered to the customer, the UK Civil Aviation Authority (CAA) uses benchmarking to compare airports with the 'best in class' (Francis et al., 2002). In other countries, including the major airports in Italy, Aéroports de Paris, and Budapest Airport, quality of service is regulated as part of the incentive regulation, for example, by integrating a factor representative of service quality in the price regulation formula, or applying penalties to airports not meeting a set minimum quality of service standard (Rovizzi and Thompson, 1992; Adler et al., 2015). 


\section{Quality of service monitoring at Australian airports}

This article focuses on the quality of service monitoring and reporting approach used by the ACCC as part of the LHR. The ACCC has monitored the quality of service at major Australian airports since July 1997. At that time, monitoring was used to complement an airport-specific price regulation regime comprising price monitoring, price caps and 'show cause' procedures for new investments (Littlechild, 2012). However, in its first review, the PC (2002) concluded that the informational challenges confronting the price control regime risked regulatory failure by distorting production decisions and 'chilling' airport investment. The price controls were therefore replaced by the LHR which includes no direct regulatory control over prices, revenues or profits, but instead monitors airport prices and quality of service levels. Following the recommendations of the PC in the latest review (PC, 2011), the Government directed the ACCC to continue price and quality of service monitoring at Brisbane, Melbourne, Sydney, and Perth airports until June 2020. This approach is commonly referred to as 'sunshine regulation' and is based on the analysis and publication of performance results in comparison with other operators within the same sector (Marques, 2006; Marques and Brochado, 2008). Through the reporting and publication of this information, it is expected that operators whose quality of service performance is poor are pressured by the media, politicians and consumers to correct any deficiencies (Marques and Brochado, 2008).

The approach currently used by the ACCC to monitor quality of service combines objective measures from airport operators and subjective measures from airport users. The focus is on service criteria related to passengers (e.g., check-in, immigration, amenities, etc.) and airlines (e.g., runway, taxiways, aprons, etc.). These criteria have been developed in consultation with the Australian Commonwealth Department of Infrastructure and Regional Development and the Treasury (ACCC, 2014). The ACCC states that quality of service monitoring is a "complement to prices monitoring because rather than increasing prices, an airport may take advantage of market power by saving money through the lowering of service standards" (ACCC, 2016, p.175). In fact, while overall prices charged by airports increased substantially over the last eleven years, the ACCC's published reports show only marginal improvements in quality of service levels over the same period (ACCC, 2016). Airports reject this finding, pointing towards what they consider to be a poor methodology used by the ACCC, particularly in terms of the transparency of methodological details, the representativeness of the samples and the reliability and validity of the data collected (e.g., Finch et al., 2010). This criticism, 
and considering the importance of public transparency as part of the sunshine regulation approach, point to the necessity to investigate the approach used by ACCC in greater depth.

\section{Methodology}

This research is based on a combination of secondary and primary data. Secondary data predominantly included the review and integration of the PC’s 'Economic Regulation' reports, as well as the 'Airport Monitoring' results and other reports published by the ACCC. In turn, primary data were collected through semi-structured interviews conducted with 21 experts (see Table 1), each lasting between 45 to 60 minutes.

A combination of airport and airline executives, as well as government regulatory managers, consultants and academics were invited to participate in the interviews. Seven chief financial officers (CFO) of the major Australian capital cities and regional airports participated in this research as well as one from New Zealand who had extensive experience with the Australian regulatory framework. Airport CFOs were used as the research presented in this paper comprised of a large-scale project that identified CFOs as the most senior executives able to respond appropriately to regulatory and investment topics related to the LHR. All of the leading domestic airline groups operating in Australia and a major international airline operating in Australia ( $n=5)$ also participated in the study. The remaining interviewees included representatives from government regulatory bodies, various aviation-related associations and leading Australian academics with extensive experience in the underlying research topic $(n=6)$. Most interviews were conducted face-to-face in six different cities in Australia and one in an overseas location, between March and August 2015.

\section{Table 1: Details of the research sample}

\begin{tabular}{lll} 
ID & Background & Description of respondents' background \\
\hline 1 & Airline & Executive of a low-cost carrier \\
2 & Airline & Executive of a leading airline group in Australia \\
3 & Airline & Executive of a leading airline group in Australia \\
4 & Airline & Executive of an international airline group operating in Australia \\
5 & Airline & Executive of a regional airline \\
6 & Airline & Representative of an aviation association \\
7 & Airline & Representative of an airline association \\
8 & Airport & Representative of an airport association \\
9 & Airport & CFO of a predominantly low-cost airport
\end{tabular}


A total of 17 participants agreed to have the interviews audio recorded. The recorded interviews were professionally transcribed and sent back to each interviewee for revision, including suggestions for necessary changes. In the four cases where permission was not given to record the interviews, notes were taken. A first draft of the present paper was sent to each interviewee for their consent and feedback before this article was submitted for publication. The transcribed interviews were coded using the NVivo software. The following relevant nodes were used during the analysis of the interview transcripts: a) 'Regulator: PC and ACCC’ (14 sources; 42 references); and b) 'Monitoring regime \& quality' (14 sources; 52 references). The notes from the four remaining interviewees were used to complement and support some of the results obtained.

The following section continues with an in-depth examination of the ACCC monitoring approach by using secondary data. Doing so sets the basis for examining the stakeholders' perceptions of the monitoring approach, which is presented in the second part of the analysis.

\section{Secondary data analysis - A review of the ACCC monitoring approach}

\section{Overview of the methodology used}

A key aim of monitoring the quality of service is to publicly report an airport's performance, and by doing so, discourage its operator from lowering service standards (ACCC, 2014). In order to achieve this aim, the ACCC focuses on measuring the quality of service levels that are in the control of the airport operator and excludes services that are provided by other providers. For example, terminals which are leased by airlines are not subject to quality of service monitoring. The assessment of the quality of service is informed by objective data from the 
Table 3: Indicators of quality of passenger-related services and facilities (domestic and international) 


\begin{tabular}{|c|c|c|}
\hline Category & Indicator & Data source \\
\hline \multirow[t]{4}{*}{ Check-in } & Check-in availability & Airline survey \\
\hline & Check-in standard & Airline survey \\
\hline & Check-in waiting time & Passenger survey \\
\hline & Number of departing passengers per check-in desk, kiosk and bag drop facility (peak hour) & Objective indicator \\
\hline \multirow[t]{5}{*}{ Immigration } & Waiting time in outbound Immigration area $^{\#}$ & Passenger survey \\
\hline & Number of departing passengers per outbound Immigration desk (peak hour) ${ }^{\#}$ & Objective indicator \\
\hline & Waiting time in inbound Immigration area & Passenger survey \\
\hline & Number of arriving passengers per inbound Immigration desk (peak hour) ${ }^{\#}$ & Objective indicator \\
\hline & Number of arriving passengers per baggage inspection desk (peak hour) ${ }^{\#}$ & Objective indicator \\
\hline \multirow[t]{4}{*}{ Information } & Flight information display screens & Passenger survey \\
\hline & Number of passengers per flight information display screen (peak hour) & Objective indicator \\
\hline & Number of passengers per information point (peak hour) & Objective indicator \\
\hline & Signage and wayfinding & Passenger survey \\
\hline \multirow[t]{7}{*}{ Baggage } & Baggage processing facilities availability & Airline survey \\
\hline & Baggage processing facilities standard & Airline survey \\
\hline & Average throughput of outbound baggage system (per hour) & Objective indicator \\
\hline & Circulation space for inbound baggage reclaim & Passenger survey \\
\hline & Number of arriving passengers per $\mathrm{m}^{2}$ of inbound baggage reclaim area (peak hour) & Objective indicator \\
\hline & Findability of baggage trolleys & Passenger survey \\
\hline & Number of passengers per baggage trolley (peak hour) & Objective indicator \\
\hline \multirow[t]{4}{*}{ Gate lounges } & Seating in lounge area (quality and availability) & Passenger survey \\
\hline & Number of departing passengers per seat in gate lounges (peak hour) & Objective indicator \\
\hline & Crowding in lounge area & Passenger survey \\
\hline & Number of departing passengers per $\mathrm{m}^{2}$ of lounge area (peak hour) & Objective indicator \\
\hline \multirow[t]{2}{*}{ Amenities } & Standard of washrooms & Passenger survey \\
\hline & Number of departing passengers per washroom (peak hour) & Objective indicator \\
\hline \multirow[t]{6}{*}{ Aerobridges } & Aerobridges availability & Airline survey \\
\hline & Aerobridges standard & Airline survey \\
\hline & Percentage of international passengers arriving using an aerobridge $\mathrm{e}^{\#}$ & Objective indicator \\
\hline & Percentage of international passengers departing using an aerobridge ${ }^{\#}$ & Objective indicator \\
\hline & Number of arriving domestic passengers per aerobridge (peak hour) ${ }^{\wedge}$ & Objective indicator \\
\hline & Number of departing domestic passengers per aerobridge (peak hour) ${ }^{\wedge}$ & Objective indicator \\
\hline Security & Quality of security search process & Passenger survey \\
\hline
\end{tabular}


* Check-in services and facilities include: Check-in counters, IT systems and queuing areas; refers only to check-in services and facilities that are managed by the airport operator, not instances where an airline is the manager of the check-in service or facility.

${ }^{\wedge}$ Indicator used for evaluating the quality of passenger-related services and facilities at the domestic terminal only.

\# Indicator used for evaluating the quality of passenger-related services and facilities at the international terminal only. 
As part of its methodology, the ACCC conducts a survey asking airport users to rate the availability and standard of the airport operator's services and facilities. 'Availability' refers to the capacity of an airport operator's services or facilities, while 'standard' reports on the perception of the provided services (ACCC, 2014). The scale used to evaluate the individual services and facilities includes a five-point scale ranging from 'very poor' to 'excellent'. The calculated averages from the respective data were reported and rounded up to the respective rating using 1.00-1.99 for 'very poor', 2.00-2.99 for 'poor' and so on in the reports before the 2014-15 report. Since the 2014-15 report, a new scale was used, with 1.00-1.49 associated with 'very poor', 1.50-2.49 with 'poor' and so forth (ACCC, 2016). Ratings of 3.00 (i.e., satisfactory) and above suggest that the service is provided at an efficient level (ACCC, 2014). When survey participants rate a service or facility below the satisfactory level, the ACCC requests additional information to explain the low rating.

The ACCC acknowledges some limitations in its service monitoring approach. One of them is that passengers' perceptions may not adequately reflect the actual quality of service. First, individual aspects of the airport service might be influenced by services and facilities provided by other parties, including the airlines (ACCC, 2014). This is because airport services should be seen as a process (Chen and Chang, 2005), or as a part of the air transport value chain (Tretheway and Markhvida, 2014), comprised of multiple interlinked activities which collectively contribute to passengers' overall perception of service quality (Fodness and Murray, 2007). Furthermore, similarly to some established quality of service measurement instruments (e.g., ASQ survey), the instruments used by the ACCC have not been tested on their validity and reliability (Bezerra and Gomes, 2016). As a result, it cannot be determined with certainty whether the instruments used do in fact measure what they intend to measure (i.e., validity), and whether the reported results can be compared across the monitored airports or generate comparable outcomes when repeatedly used at one airport (i.e., reliability).

\section{Sampling and reporting}

Not all service aspects necessarily have the same relevance to its user. In fact, airport users can vary substantially in their needs and requirements and subsequently also in their perception of quality of service (e.g., Fodness and Murray, 2007; Pantouvakis and Renzi, 2016). For example, primary service segments for airlines include runway capacity, taxiways, terminal 
infrastructure, ground services, and airport traffic control. Passengers might not even be aware of these service elements, but instead are more concerned with ease of access, processing times, and airport amenities. Also, passengers might have very different needs (e.g., long-haul international vs short-haul domestic; business vs leisure travellers) and so might airlines (e.g., full-service vs low-cost carriers). As shown in Table 2, the ACCC partly accounts for these differences by distinguishing between services provided to passengers, airlines and landside operators, respectively.

Passenger perception surveys are arranged by the respective airports consistent with the specifications set out in the Airports Regulations and Quality of Service Guidelines (ACCC, 2014). The areas covered in the passenger surveys include check-in, security clearance, government inspection, gate lounges, washrooms, baggage processing and trolleys, signage and wayfinding, car parking and airport access for arriving and departing passengers. The results are reported as averages and compared between domestic and international services (ACCC, 2016). The ACCC additionally incorporates objective data related to the respective airport, including the number of passengers at peak hours, the number of aerobridges, and the size of gate lounges. Given its significance as a non-aeronautical revenue stream, car parking services including alternative airport access options are monitored and reported separately.

In regards to airline surveys, the ACCC sends the surveys directly to the major domestic airlines (i.e., Qantas, Jetstar, Tiger Airways, and Virgin Australia), while using the Board of Airline Representatives of Australia (BARA) as the body representing international airlines operating in Australia. The ACCC does not disclose which airlines have participated in the surveys nor does it distinguish between international and domestic airlines in the reporting of the results. However, it reports the results on a range of aircraft-related services and facilities, including runway, taxiways, aprons, aircraft parking, ground handling and management responsiveness. Finally, since 2014, the ACCC also surveys landside operators including taxi associations, bus associations and selected off-airport car parking operators about the airports' landside operations.

\section{Primary data analysis - A stakeholder perspective}

Following the in-depth review of the ACCC airport quality of service monitoring approach including the results reported over the last five years, this section goes one step further by 
presenting a stakeholder perspective. The focus is on analysing how main stakeholder groups, that is, those who are affected by or are involved in the LHR and the related airport quality of service monitoring, perceive the current approach used by the ACCC. Accordingly, the 21 interviews were clustered into three different groups: a) 'Airports;' b) 'Airlines;' and c) 'Others,' with the latter comprising government regulatory managers, academics and consultants.

Table 4 provides an overview of how stakeholders perceived the ACCC airport quality of service monitoring approach. The insights provided by 12 interviewees could not be clearly categorised as a supporting or opposing standpoint. Yet, they still offered valid perspectives on the themes covered in this research. Three out of eight airport representatives did not support the current approach, while two were in favour. Among airline representatives, two were in favour, while one was not. Most airline representatives, as well as interviewees within the 'Others' group, did not take a clear standpoint. In the following sections, the different perspectives taken by the three stakeholder groups are analysed in greater depth. 
Table 4: Overview of perspectives taken by key stakeholder groups

\begin{tabular}{|c|c|c|c|c|c|c|c|c|c|}
\hline \multirow{2}{*}{$\begin{array}{l}\text { Stakeholder } \\
\text { Perception }\end{array}$} & \multicolumn{3}{|c|}{ Airports $(n=8)$} & \multicolumn{3}{|c|}{ Airlines $(n=7)$} & \multicolumn{3}{|c|}{ Others $(n=6)$} \\
\hline & In support & In opposition & No standpoint & In support & In opposition & No standpoint & In support & In opposition & No standpoint \\
\hline$n$ & 2 & 3 & 3 & 2 & 1 & 4 & 1 & -- & 5 \\
\hline Key insights & $\begin{array}{l}\text { Positive comm } \\
\text { Reports provid } \\
\text { Negative comn } \\
\text { Analysis/repor } \\
\text { Scale needs im } \\
\text { Airlines could } \\
\text { Relevance of t } \\
\text { widely used } \\
\text { Services provi }\end{array}$ & $\begin{array}{l}\text { transparency } \\
\text { eent } \\
\text { ed towards low } \\
\text { eys is question } \\
\text { airlines can inf }\end{array}$ & ASQ surveys are & $\begin{array}{l}\text { Positive comn } \\
\text { Reports give } \\
\text { Methodology } \\
\text { Negative com } \\
\text { Analysis/repo } \\
\text { Analysis does } \\
\text { ACCC lacks } \\
\text { identified issu } \\
\text { All airlines ar } \\
\text { of dependency }\end{array}$ & $\begin{array}{l}\text { the airlines } \\
\text { transparency } \\
\text { ve behind the d } \\
\text { enforcing the } \mathrm{i} \\
\text { the same weigh }\end{array}$ & entation of & $\begin{array}{l}\text { Positive comn } \\
\text { Approach and } \\
\text { Negative com } \\
\text { Reports lack i } \\
\text { influencing th } \\
\text { Analysis does } \\
\text { investments } \\
\text { Reports tend t } \\
\text { Monitoring ap } \\
\text { service quality }\end{array}$ & $\begin{array}{l}\text { th analysis of th } \\
\text { olts } \\
\text { onsider the effe } \\
\text { our airlines over } \\
\text { h encourages m }\end{array}$ & $\begin{array}{l}\text { for its purpose } \\
\text { eness of } \\
\text { sengers } \\
\text { num levels of }\end{array}$ \\
\hline
\end{tabular}




\section{Airports}

A total of eight airport representatives provided comments on the ACCC approach with three interviewees representing monitored airports. Because airports are more directly impacted by the results of the ACCC reports, the interviewees had a more detailed view on some of the issues related to the methodology than did the airlines. Those airport representatives supporting the current methodology stated that the ACCC reports are conducted independently, therefore providing an external perspective which is "quite high level in terms of giving a guide of how the airport is performing both financially and from a quality of service." In contrast, those who did not support the current methodology perceived that there is a lack of "stronger guidelines, and that the reporting should be more transparent." Airport representatives also pointed out that most airports, whether monitored or not, use comprehensive passenger surveys, thus making the ACCC survey redundant. Respondents believe that self-monitoring and selfreporting would be sufficient as that the general public hardly pays attention to the results provided by the ACCC annual reports.

Regarding the more specific issues related to the methodology used by the ACCC, airport representatives questioned why the ACCC includes areas in its reporting over airport operators it has no control. One specific example provided was the many issues surrounding baggage handling: Airlines, particularly low-cost carriers, were criticised of being primarily interested in unloading and reloading baggage, rather than in ensuring the timely processing of the arrival luggage. While this procedure speeds up the turnaround time of aeroplanes, it delays the time in which baggage is delivered to the terminal. Baggage handling is usually outsourced to airlines or specialised companies, implying that airport operators have little no control over its processes.

Further, airport representatives described the current five-point scale (i.e., 1. Very poor; 2. Poor; 3. Satisfactory; 4. Good; 5. Excellent) used in the ACCC quality of service surveys as "misleading" because the middle-point of the scale is defined as 'satisfactory' rather than 'neutral'. By defining 'satisfactory' as the middle-point of the scale, quality of service levels might be rated lower than if the middle-point were labelled 'neutral' as commonly done in fivepoint Likert scales. Interviewees point out that if anchor (1) is 'very poor', anchor (5) should be termed 'very good', rather than 'excellent'. These insights suggest that the scale and rating 
approach as currently used by the ACCC could be improved.

Another limitation noted by an airport representative is the current sampling and reporting approach:

[W] 've spoken to the BARA; they don't know who fills them in within the airlines. We've had our people who talk to the airlines all the time, and it's none of our key contacts that fill out the surveys. It's not that we need to know the list [...but] how are they actually forming an assessment? (CFO of a capital city airport)

According to one airport representative, having details of the scores given by the individual airlines could allow the airport to solve or address the raised issues directly. Instead, airports do not know "what the airline was, or what the specific problem was [...] we've got no idea. We can't fix something we're not aware of. I think there's a potential to improve it." (CFO of a capital city airport). It was also noted that the monitoring reports do not allow airports to raise issues or complaints related to services provided by airlines, which when not being addressed, can negatively impact on the passengers’ perception of airport service quality.

Concerning the reported monitoring results, an airport representative stated that "passenger survey results change year by year, but not massively. The airline survey results particularly at the individual question level, but even overall are a lot more volatile." This difference might be explained in part by the fact that the passenger sample size is substantially larger than the one of the airlines. The small sample size makes the results reported on the airlines more susceptible to variations in the scores given by individual airlines, while, in comparison, passenger results are less volatile and arguably normally distributed owing to the larger sample size. Notably, the ACCC does not report on either the sample sizes or the response rate, nor does it report the standard deviation alongside with the calculated means in their reports.

One interviewee suggested that "the focus should be on passenger surveys because they're clearly unbiased, passengers don't have a reason to screw around with you." The same interviewee explained that the results presented by any year's report might be affected by ongoing negotiations or agreements that took place years before. Airlines, according to this interviewee, tended to give lower ratings when they were in an ongoing negotiation process with the respective airport, or when the PC undertook a review of the sector. Thereafter, the 
scores would improve. While not blaming the airlines for any intentional bias, the interviewee pointed to an identifiable pattern that is observable over the 20-year reporting history at the airport this interviewee represented.

Airport representatives additionally questioned the relevance and representativeness of the reported results. As one interviewee described:

We don't pay a lot of attention to the ACCC [passenger] surveys [...]. Because by the time the ACCC publishes it, it's nine months after the end of the year it's reported on. Which means it's 15 months after the average statistic was recovered, which is a little bit late for management purposes. We do our own surveys, and they're done on a monthly basis, and they're done on all the same sorts of facilities as the ACCC does, plus a host of others. Those - and we also survey the airlines ourselves, that's on a more regular basis [...] we're talking to Qantas virtually daily somewhere on the airport. (CFO of a capital city airport)

The same interviewee argued that their organisation does not believe that it needs the ACCC to tell it that it is paramount to "keep the toilets clean and have a good quality product." Other interviewees pointed out that most airports use the ASQ surveys by the ACI, hence rendering the ACCC passenger service surveys unnecessary. The interviewees suggested that passenger expenditure at the airports is heavily influenced by positive experiences, especially at the international terminal:

If we run down the quality of our service, no one is going to buy cameras and perfume and sunglasses. They get to the airport two hours before they have to catch a plane. If you make that experience stress-free, people will buy retail. (CFO of a capital city airport)

The same interviewee also recognised that airports are still far from providing a more customerorientated environment. This interviewee underscored this view with an example of how international passengers are often treated during the security screening procedure:

[They] are greeted by a rude person saying take your laptop out and take your aerosols out of your bag. That's the first thing you get. My view is they should be greeted by somebody saying: welcome to [the] airport [...] as a broader business person I can't 
see how giving poor service is good for business. It has to be good. So even if I can't see a correlation, I know that it has to be good. I don't need the ACCC to tell me that. (CFO of a capital city airport)

A representative of a non-monitored airport complemented the above arguments by stating that airports produce "much more fulsome and detailed service level reviews than what is in the ACCC report." He asserted that there is no problem with the government looking at the profitability of airports and the service levels they provide. However, the experience at an airport should be seen as "part of the passengers' journey" which means that the airport service quality can be affected by the service provided by airlines and other players. Thus, according to the same interviewee, the service offered by the airlines and the airports together should be considered to generate a more comprehensive understanding of the quality of service.

It is also for this very reason that airlines should be willing to invest in the improvement of the airport experience rather than focusing on operational efficiency only. Airport representatives suggested that some low-performance scores are a consequence of not finding a timely agreement with airlines. Reaching agreement on infrastructure investments was described as a particularly lengthy and complex process for multi-user airline terminals because of the requirement of accommodating the needs put forward by different airlines (e.g., full-service vs low-cost carriers). In fact, airport representatives reported that the terminals that are operated solely by one airline tend to perform consistently higher in the ASQ surveys. Finally, the interviewees pointed to a number of new agreements which have recently been negotiated with the aim of improving airport services. These improvements, according to the interviewees, will lead to higher results over the next years.

\section{Airlines}

Seven airline executives were interviewed on the subject of this research. One interviewee, a representative from a major domestic airline, did not support the ACCC approach. This interviewee's response was similar to many airport representatives, suggesting the superior quality of the numerous surveys already conducted within the industry. In turn, two airline representatives, while in support of the monitoring regime, also criticised that the current methodology used by the ACCC because it does not distinguish between domestic and international operations. Specifically, airline representatives pointed out that the analysis does not "delve behind the data; [i]t just really picks up the data and reports, and says, oh there's 
a trend." One interviewee from a domestic low-cost airline stated that "the monitoring methodology generally works... [with] the methodology itself [being] pretty sound." However, the same interviewee also perceived that the current monitoring approach has " a lack of power." This interviewee referred to the capabilities possessed by the ACCC to address and enforce the implementation of any issues that are identified within the monitoring reports. A representative of a major domestic airline shared a similar view, suggesting that the monitoring approach is more a tool for the airports to improve their services, rather than an instrument to enforce changes.

Regarding the airline feedback section within the ACCC reports, airline representatives, on the one hand, noted that the reporting standards of "the reports are quite high [...] particularly [in terms of] airline feedback" (Executive of a leading airline group). On the other hand, the same interviewee pointed out that the airlines' feedback is not weighted in terms of its importance to a particular airport. For example, while some airlines might have a large market-share and are therefore highly dependent on an airport, other carriers might operate only one flight per day to a given airport. Nonetheless, within the reports, all airline ratings are given the same weight in the determination of the quality of service levels.

Another airline representative highlighted that, on several occasions, their airline has publicly put forward statements to the PC and other industry forums proposing that "there should be stronger guidelines and that the reporting should be more transparent." The following example highlights the underlying issue:

When security regulations were brought in, it was intended obviously for the protection of passengers, and that any costs associated with it should be a direct pass-through. We now have airports wanting to profit off that, and they write it in their document; we're entitled to earn profit. We're saying, hang on a minute - that is not acceptable this should be a cost - it's a community cost - it's a mandated cost the government puts on us to protect passengers and our country - it's not an opportunity for an airport to make another level of profit on it. So there should be stronger guidelines. (Executive of a leading airline group)

Airlines take the view that they should only be involved in supporting investments that improve capacity and contribute to the operation of aeroplanes. Any improvements in 'beautifying' the 
airport should be dealt with by the airport operator and in consultation with the local community. For example, when an airport is to be portrayed as an icon for a destination, or when an airport seeks to redevelop its facilities for sole the purpose of providing a more cosmetic appeal, airlines should not be charged higher prices. Airline interviewees consider that these types of investment are unlikely to generate a higher traffic for the airlines or contribute to safety procedures.

A representative of a major domestic airline provided the following statement which summarises the current perception among airlines not only in terms of the methodology as used by the ACCC but also regarding the impact the yearly reports have:

Every year they [ACCC] do their annual review of the airports [...] what you'll see naturally coming through is the airports generally making very good returns on their investment. But at the same time, you will also see a lot of service - the quality of the terminals and the service at that those terminals is deteriorating as well. So I think the monitoring reports are good [...] they're quite [of a] high level in terms of giving a guide to how the airport is performing both financially and from a quality of service. But, that's as good as that framework does. It just highlights the issue. The challenge that we, as airlines have, [... is] that airports are natural monopolies, and there is no simple arbitration between an airline and an airport to determine what [... should be invested in]. [The] airport decides to build it anyway because they know they can get a return on it and that's what they think is best for the industry. (Executive of a leading airline group)

\section{Other organisations}

Out of the six interviews that were conducted with representatives not associated with either airlines or airports, only one made a clear statement in support of the ACCC approach. This interviewee, a representative of a government organisation that had a close link to a government regulatory agency, stated that passengers usually have a more favourable view of airports and suggested that there is no point in giving passengers a stronger voice in their evaluation. This interviewee also mentioned that the methodology has recently been improved (see ACCC, 2014) and can be considered effective for its current purpose.

Among the remaining interviewees who did not have a clear standpoint, one consultant with 
experience in working for a major airline, criticised that the current approach does not consider whether recent airport investments were actually made in the right place. This interviewee argued that instead of focusing on improving operational efficiency or quality of service levels, airports might focus primarily on investments that have the highest potential for profits. In contrast, an academic with extensive experience in the field stated that when examining the reports over the years, it seems the methodology favours the airlines:

It's always the same kind of message that comes out each year - airports charging too much for parking, the service isn't improving. I think it comes down to the metrics that they judge customer service by, and there's some disagreement amongst the airports that those might not be the most appropriate metrics to judge whether people are happy with the airport. The airports do a lot of their own engagement with customers to find out what's working at the airport [and] what's not.

The same interviewee suggested that ultimately, the process should be about facilitating commercial negotiation between the airlines and the airports on future infrastructure investment decisions. This interviewee argued that there is nothing stopping the airlines from walking away and not flying to a given airport. The interviewee further stated that the problem with the current format of the ACCC monitoring approach is that it does not identify what kind of work is taking place behind the scenes to provide a better understanding of the evaluations that the airports receive. She/he summed up her/his standpoint by asking:

[Are there] better ways to gauge what the airports are doing rather than just bottomline dollar investment, versus their survey outcomes? [Airports] are doing significant projects and on a service delivery improvement to try and facilitate that, but you know, a lot of them are long-term investments as well.

Another academic suggested that the current monitoring regime aims to provide "a minimum level of quality. Not necessarily to give it hopeless quality, but that there is an incentive to keep quality at sort of the acceptable minimum but not below." According to the same interviewee, the current regime does not provide much incentive to improve quality unless airlines are prepared to pay more. This interviewee referred to the example of aerobridges, where some airports are only willing to provide them if airlines pay for them. 
Finally, a public servant with a long-standing work experience in the regulation and monitoring of Australia's airports suggested that in general, passenger survey results are more positive than the feedback given by the airlines. While this interviewee acknowledges that passengers might not always have a clear understanding of what airports provide in terms the various services (e.g., immigration, check-in, lounges, etc.), they tend to take a more favourable perspective than do the airlines. These differences between the two customer groups might either be related to lower levels of expectations set by passengers or to the airlines using their voice to put pressure on airports or to express their dissatisfaction with the current LHR approach.

\section{Discussion and Implications}

This article aimed to investigate the quality of service monitoring approach currently in place as part of the LHR at Australian airports. This investigation included a comprehensive review of the current methodology used by the ACCC to monitor and report the quality of airport services. Also, the article provided insights into how key stakeholders, including representatives from Australia's major airports and airlines, perceive the current approach to quality of service monitoring. As such, the research, not only critically examined but also holistically captured the viewpoints of those directly affected by the LHR regime in general and the service monitoring approach in particular.

The insights evolving from this investigation have some important implications for air transport management and policy. Foremost, the review of the methodology, which is currently used by the ACCC for monitoring the airports' quality of service levels, suggests some important limitations. Based on the recommendations set by the PC (2011) particularly concerning the interpretation of service quality outcomes, the ACCC conducted a comprehensive review with the aim of increasing the transparency of the results (ACCC, 2014). While this review led to some improvements (e.g., the way how computed averages from the respective data are rounded up and down), some important limitations persist. Both airport and airline representatives point to issues related to the current methodology, including the transparency of the sample and data, the weighting of the results, and the impact of the annual reports.

Firstly, the scale used by the ACCC to evaluate the individual services and facilities includes a five-point scale ranging from 'very poor' to 'excellent' (ACCC, 2016). This scale, as also 
highlighted in the interviews, is problematic when reporting averages because it does not apply a Likert-type scale with both anchors being weighted equally. For example, surveys commonly use the anchors 'strongly disagree' and 'strongly agree' as the anchors for a five- or sevenpoint scale. This scale allows for the computation of averages because one can assume similar differences between the individual scale points (e.g., the difference between 'strongly disagree' and 'disagree' vs difference between 'strongly agree' and 'agree'). However, this is not possible for the five-point scale currently used by the ACCC because it is not clear whether, for example, the difference between 'very poor' and 'poor' equals the difference between 'good' and 'excellent'. Thus, the current scale will need to be updated to allow for its effective application.

Secondly, the quality of service measure as used by the ACCC does not weigh the importance of the individual indicators or categories for the respective user. As noted by previous studies, quality of service comprises multiple interlinked elements, yet not all airport services might be equally important to the respective user (Fodness and Murray, 2007; Tsai et al., 2011; Bogicevic et al., 2013). For example, passengers might perceive the check-in waiting time as critically important, while information displays for inbound baggage reclaim might be completely irrelevant to them. In other words, not all services provided by an airport will necessarily have the same relevance for each user. As pointed out by both airline and airport representatives, the same disparity can also apply to airlines, specifically when distinguishing between national or international, or full-service and low-cost carriers. These differences need to be accounted for in the analysis and reporting of the results to make them more representative of the actual perception of service quality. Thus, and as noted by an airport representative, the methodology should consider the influence of airline-related services which potentially might impact on the passengers' perception of airport service quality.

Thirdly, limited information is disclosed by the ACCC concerning the size and descriptive statistics of the respective samples (i.e., domestic and international travellers, and airlines). In addition, no standard deviations are reported in addition to the calculated averages. This reporting approach is problematic, particularly when the sample is small $(\mathrm{n} \leq 100)$ because possible variations in responses can distort the results (Hair et al., 2006). As highlighted by airport representatives, variations are more likely to occur in the reported results from the airline surveys because of the small sample sizes. The reporting of averages without disclosing 
the standard deviation could lead to the annulment of relevant rating differences (e.g., differences in ratings provided by low-cost and full-service carriers). In order to improve the transparency of the reported results, as well as to ensure a more meaningful interpretation, it will be important to disclose more details on the sample characteristics (e.g., sample sizes, demographics, domestic vs. international travellers, business vs. leisure travellers, national vs. international airline, use frequency of the specific airport, etc.). In fact, the improvements in transparency have been identified as a key issue by all three stakeholder groups.

Apart from the three limitations related to the current methodology, interviewees representing the airlines additionally pointed out that the ACCC and the current monitoring approach 'lack power' because there is no mechanism dealing with the findings made in the yearly reports (i.e., high prices or low levels of quality of service). This problem has also been highlighted in a public announcement by Qantas Airways (2012) pointing out that there is no ability for airport users to seek the maintenance of or improvements to services or, alternatively, demand reduced prices where services or facilities are not performing to the regulated standards. In turn, airport representatives highlighted in the interviews that service improvement efforts are often difficult to negotiate, particularly in cases where investments do not improve operational efficiency for airlines or are made in terminals which are used by airlines with different needs.

The absence of the link between the investments made by airports and quality of service results reported by the ACCC undermines the effectiveness and impact of the monitoring approach. The ACCC (2012) notes that over the eleven years of quality of service monitoring, the passenger survey results have been relatively stable from year-to-year, remaining unresponsive even to significant infrastructure investments. Further, imposing improvements solely based on airline survey results might not be practicable as airlines might be commercially motivated to provide, for example, low ratings for aspects that have not been successfully negotiated. In the interviews, airport representatives suggest that independent ASQ surveys provide them with a more detailed and timely indication of where investments need to be made to maintain appropriate quality service levels. In a public statement, Perth Airport (2013) even suggests that quality of service monitoring is no longer relevant as the nature of the commercial agreements between the airport and airlines has changed dramatically, covering almost every aspect of the airline/airport relationship, and the experience of passengers.

Following from the insights generated from the interviews as well as the review of the 
methodology, it seems that the quality of service monitoring is not effective in its current form. A key mechanism of the LHR is an independent regulatory body imposing a 'credible threat' of stronger regulation to cases of abuse of market power (Forsyth, 2008; Gillen, 2011; Lohmann and Trischler, 2017). While the Australian Government reserves the right to reimpose stricter controls in cases where the abuse of market power is evident (Littlechild, 2012; Arblaster, 2014), it is unlikely that these controls can be enforced by the ACCC. This is because the current methodology does not allow for an in-depth analysis of whether poor quality of service results are indeed a result of delayed investment in, or a lack of, specific airport infrastructure. In fact, it is not possible to evaluate whether the key aims set by the Australian Government are met under the LHR (Productivity Commission, 2011), namely to encourage airports to conduct infrastructure investments that ensure both efficiency of ongoing airport operations and appropriate levels of service quality. Moreover, owing to its limitations it is questionable as to whether the ACCC monitoring might actually meet the underlying aim of the 'sunshine regulation', that is, publicly pressuring airports to correct any deviations by publishing and comparing performance results (cf. Marques, 2006; Marques and Brochado, 2008). It is suggested here that not only would an improved methodology lead to greater transparency, but that it would also allow for a more informed evaluation and comparison of airport performance, which is key to the LHR (Adler et al., 2015).

\section{Conclusion}

This article investigated quality of service monitoring as a central element of the current LHR at Australian airports. The investigation included a critical analysis of the methodology used by the ACCC to monitor and report the quality of airport services. Also, the perception of the monitoring approach among key stakeholder groups was incorporated to generate a more holistic perspective. Based on the findings of this investigation, this article concludes that the monitoring approach is underpinned by some limitations restricting its effectiveness, reliability and validity. In fact, considering the perception and limitations of the current format, one might well ask whether the quality of service monitoring is effective and therefore necessary. Asking this question is important when considering the administration costs involved in service monitoring process.

Future research will be required to test the validity and reliability of the current quality of 
service measure, and to explore alternative measures that might be applied. For example, many airports apply the ASQ survey to measure and compare their performance against industry best practices. Also, future research should investigate to what extent airports would consider intentionally letting the quality of service standards deteriorate. Airports are increasingly required to diversify their revenue streams by relying not only on aeronautical charges but also on non-aeronautical charges derived from, for example, real estate and retailing. It might well be argued that airports as service businesses do understand that higher customer spending and ultimately the profitability of a firm is based on a positive perception of service quality and customer satisfaction. However, given the market power possessed by Australia's monitored airports, this argument is only speculative and requires further investigation. 


\section{References}

ACCC (2012), Airport Quality of Service Monitoring - Discussion Paper for Review of Quality of Service Monitoring, Canberra: Australian Competition and Consumer Commission.

ACCC (2014), Guideline for Quality of Service Monitoring at Airports, Canberra: Australian Competition and Consumer Commission.

ACCC (2016), Airport Monitoring Report 2014-15, Canberra: Australian Competition and Consumer Commission.

ACI (2016), Annual Report: The voice of the world's airports, Montreal: Airports Council International.

ACI (2017a), Airport Ownership, Economic Regulation and Financial Performance, Montreal: Airports Council International.

ACI (2017b), ASQ Survey - Methodology, available at http://www.aci.aero/Airport-ServiceQuality/ASQ-Services/Methodology.

Adler, N., Forsyth, P., Mueller, J. and Niemeier, H.-M. (2015), "An economic assessment of airport incentive regulation", Transport Policy, Vol. 41, pp. 5-15.

Arblaster, M. (2014), "The design of light-handed regulation of airports: Lessons from experience in Australia and New Zealand", Journal of Air Transport Management, Vol. 38, pp. 27-35.

Arblaster, M. (2016), "Negotiate-arbitrate regulation of airport services: Twenty years of experience in Australia", Journal of Air Transport Management, Vol. 51, pp. 27-38.

Bezerra, G.C.L. and Gomes, C.F. (2016), "Measuring airport service quality: A multidimensional approach", Journal of Air Transport Management, Vol. 53, pp. 8593.

Bogicevic, V., Yang, W., Bilgihan, A. and Bujisic, M. (2013), "Airport service quality drivers of passenger satisfaction", Tourism Review, Vol. 68 No. 4, pp. 3-18.

Board of Airline Representatives of Australia (2012), Scope of Airport Quality of Service Monitoring, Sydney: Board of Airline Representatives of Australia.

Chen, F.-Y. and Chang, Y.-H. (2005), "Examining airline service quality from a process perspective", Journal of Air Transport Management, Vol. 11 No. 2, pp. 79-87.

De Nicola, A., Gitto, S. and Mancuso, P. (2013), "Airport quality and productivity changes: A Malmquist index decomposition assessment", Transportation Research Part E: Logistics and Transportation Review, Vol. 58, pp. 67-75.

Finch, S., Collins, M. and Gordon, I. (2010), Methodological Review of the ACCC Airport Monitoring Report, Melbourne: The University of Melbourne. 
Fodness, D. and Murray, B. (2007), "Passengers' expectations of airport service quality", Journal of Services Marketing, Vol. 21 No. 7, pp. 492-506.

Forsyth, P. (2008), "Airport policy in Australia and New Zealand: Privatization, light-handed regulation, and performance", Aviation Infrastructure Performance: A Study in Comparative Political Economy, Madrid: Fundacion Rafael del Pino, pp. 65-99.

Francis, G., Humphreys, I. and Fry, J. (2002), "The benchmarking of airport performance", Journal of Air Transport Management, Vol. 8 No. 4, pp. 239-247.

Fu, X., Homsombat, W., and Oum, T.H. (2011), Airport-airline vertical relationships: Their effects and regulatory policy implications, Journal of Air Transport Management, Vol. 17, pp. 347-353.

George, B.P., Henthorne, T.L. and Panko, T.R. (2013), "ASQual: Measuring tourist perceived service quality in an airport setting", International Journal of Business Excellence, Vol. 6 No. 5, pp. 526-536.

Gillen, D. (2011), "The evolution of airport ownership and governance", Journal of Air Transport Management, Vol. 17 No. 1, pp. 3-13.

Hair, J.F., Black, W.C., Babin, B.J., Anderson, R.E. and Tatham, R.L. (2006), Multivariate Data Analysis, Upper Saddle River: Pearson.

Littlechild, S.C. (2012), "Australian airport regulation: exploring the frontier", Journal of Air Transport Management, Vol. 21, pp. 50-62.

Lohmann, G. and Trischler J. (2017), "Licence to build, licence to charge? Market power, pricing and the financing of airport infrastructure development in Australia", Transport Policy, Vol. 59, pp.28-37.

Marques, R.C. (2006), "A yardstick competition model for Portuguese water and sewerage services regulation", Utilities Policy, Vol. 14 No. 3, pp. 175-184.

Marques, R.C. and Brochado, A. (2008), "Airport regulation in Europe: Is there need for a European observatory?", Transport Policy, Vol. 15 No. 3, pp. 163-172.

Merkert, R. and Assaf, A.G. (2015), "Using DEA models to jointly estimate service quality perception and profitability: Evidence from international airports", Transportation Research Part A: Policy and Practice, Vol. 75, pp. 42-50.

Pantouvakis, A. and Renzi, M.F. (2016), "Exploring different nationality perceptions of airport service quality", Journal of Air Transport Management, Vol. 52, pp. 90-98.

Perth Airport (2013), Airport Quality of Service Monitoring, Perth: Perth Airport.

Polk, A. and Bilotkach, V. (2013), "The assessment of market power of hub airports", Transport Policy, Vol. 29, pp. 29-37.

Productivity Commission (2002), Price Regulation of Airport Services, Canberra: 
Productivity Commission.

Productivity Commission (2011), Economic Regulation of Airport Services, Canberra: Productivity Commission.

Qantas Airways (2012), Airport Quality of Service Monitoring. Sydney: Qantas Airways.

Rovizzi, L. and Thompson, D. (1992), "The regulation of product quality in the public utilities and the Citizen's Charter", Fiscal Studies, Vol. 13 No. 3, pp. 74-95.

Starkie, D. (2002), "Airport regulation and competition", Journal of Air Transport Management, Vol. 8 No. 1, pp. 63-72.

Tretheway, M.W. and Markhvida, K. (2014), "The aviation value chain: Economic returns and policy issues", Journal of Air Transport Management, Vol. 41, pp. 3-16.

Tsai, W.-H., Hsu, W. and Chou, W.-C. (2011), "A gap analysis model for improving airport service quality", Total Quality Management \& Business Excellence, Vol. 22 No. 10, pp. 1025-1040.

Vogelsang, I. (2002), "Incentive regulation and competition in public utility markets: A 20year perspective", Journal of Regulatory Economics, Vol. 22 No. 1, pp. 5-27.

Yeh, C.-H. and Kuo, Y.-L. (2003), "Evaluating passenger services of Asia-Pacific international airports", Transportation Research Part E: Logistics and Transportation Review, Vol. 39 No. 1, pp. 35-48. 